\title{
Characterization of sulphate-reducing bacteria as a function of time on buried pipeline steel under cathodic protection
}

\author{
Khotso Khoele ${ }^{1,3, *}$, Onoyivwe M. Ama ${ }^{2,3}$ and David J. Delport ${ }^{1}$ \\ ${ }^{I}$ Tshwane University of Technology, Department of Chemical, Metallurgical and Materials \\ Engineering, Pretoria, South-Africa \\ ${ }^{2}$ Department of Chemical Science, University of Johannesburg, Doornfontein, 2028, \\ Johannesburg, South Africa \\ ${ }^{3}$ DST-CSIR National Center for Nanostructured Materials Council for Scientific and Industrial \\ Research, Pretoria 0001, South Africa
}

"Corresponding author: khotsokhoele@gmail.com

Received 14/04/2018; accepted 12/01/2021

https://doi.org/10.4152/pea.2021390401

\begin{abstract}
Low-carbon steel electrodes were buried in sterilized and bacterial media. The potentiodynamic polarization (PDP) and electrochemical impedance spectroscopy (EIS) were sequentially carried out on buried electrodes. The corrosion potential, on the steel electrode buried in a sterilized medium (without sulphate reducing bacteria), was found to be more negative than that of the electrode buried in the sulphate reducing bacteria (SRB) medium. Cathodic and anodic curves electrodes buried in a SRB medium showed the highest current density. Clearly, three phases were observed during the SRB growth within an incubated medium. EIS measurements showed that the effects of biofilms on steel electrodes varied with time. From the bacterial medium, EIS results showed an optimum cathodic protection (CP) potential of $-1450 \mathrm{mV} \mathrm{Cu} / \mathrm{CuSO}_{4}$. Surface morphologies of electrodes buried in bacterial media revealed dimples on the entire electrode surface, when the slow strain rate tensile test (SSRT) was carried out in air, while quasi-cleavage was discovered on the steel electrode, when the applied CP potential was $-950 \mathrm{mV} \mathrm{Cu} / \mathrm{CuSO}_{4}$. At $-1450 \mathrm{mV} \mathrm{Cu} / \mathrm{CuSO}_{4}$, corrosion products were seen all over the electrodes, and a complete cleavage occurred on them at $-1890 \mathrm{mV}$ $\mathrm{Cu} / \mathrm{CuSO}_{4}$.
\end{abstract}

Keywords: corrosion, environment, low-carbon steel, pipelines and soil.

\section{Introduction}

Occupation of soils by microorganisms was recognized in the late $20^{\text {th }}$ century $[1,2]$, and it was increasingly observed within the last two decades [3]. This could be due to a globally linear population growth, which leads to the wider utilization of various fertilizers in soils for food production. Some of the fertilizers which are predominantly utilized are nitrates $\left(\mathrm{NO}_{3}^{-}\right)$, ammonium $\left(\mathrm{NH}_{4}{ }^{+}\right)$and lactase. 
Furthermore, during hot weather or aggressive floods conditions, the evolution of microbes and microorganisms becomes extremely high [4].

Buried pipeline steels (PSs) are mostly used for long distance applications, and are certainly exposed to a diversity of soils. So, as microbes evolve, particularly during their activities, they create a biofilm. Biofilms formation is deemed to be a cause of microbiological induced corrosion (MIC). The most problematic MIC on PSs is accentuated in the presence of sulphate reducing bacteria (SRB) [5]. As the name implies, these bacteria reduce sulphates to sulphides and consume hydrogen to form hydrogen sulphite $\left(\mathrm{H}_{2} \mathrm{~S}\right)$. The consequent $\mathrm{H}_{2} \mathrm{~S}$ reacts with steel $[6,7]$ and deteriorates it by forming a galvanic couple. Comparatively, it has been discovered that staffed SRB, in soils where organic carbon from the nutrients has diminished, becomes more toxic to PSs than well fed SRB [5].

So far, the phenomenon of SRB on PSs has globally been studied [5-10]. However, there remain consistent contradictions, in terms of whether SRB biofilms, which are produced during different enzymatic reactions on the PSs surface, significantly reduce or accelerate corrosion. Abdullah et al. [5] found that SRB in the soil grow in three stages: exponential, steady and constant phases. Furthermore, corrosion rates showed to be mainly affected by SRB metabolism activity, when these produce $\mathrm{H}_{2} \mathrm{~S}$ and change the redox potential. Those occurrences are also corroborated by the work of Chen et al. [11]. It was also observed that a conglomerate of SRB has more impact than a single species in isolation, as the conglomerate increased corrosion rates by $45.5 \%$ in two months, when compared to abiotic control [12]. On the other hand, $\mathrm{Wu}$ et al. [13] discovered that the activity of SRB with highly negative $\mathrm{CP}$ on carbon SPs results in stress corrosion cracking (SCC). On the most aforementioned studies, it has been realised that an electrolyte used in reported studies creates bulk solutions. The current dilemma around coated and cathodically protected SPs is a phenomenon called cathodic disbondment (CD). Within this complexity, an electrolyte has been found to be a thin electrolyte layer [14-18]. Furthermore, essential knowledge on how $\mathrm{CP}$ and MIC relate under CD is not available in the present literature.

Considering unclear interaction of CP and MIC under CD occurrence, this study is focused on SRB characterization on coated and cathodically protected PSs. A sterilized soil simulating solution (SSS) was used for comparison. The intent was to study SRB media on SPs during their metabolic activities and phase shifts. Furthermore, an optimum cathodic protection potential under these conditions was characterized.

\section{Experiments}

\section{Materials}

The subject material in this research was a low-carbon steel pipeline specimen, with the following compositions: $0.09 \% \mathrm{C}, 1.53 \% \mathrm{Mn}, 0.29 \% \mathrm{Si}, 0.013 \% \mathrm{P}$, $0.002 \% \mathrm{~S}, 0.02 \% \mathrm{~V}$ and the remaining $\%$ was $\mathrm{Fe}$. 


\section{Solutions and microorganisms}

The sterilized soil simulating solution (SSS) was prepared by analytical reagents consisting mainly of sodium $\left(\mathrm{Na}^{+}\right) ; 5.84 \mathrm{~g} / \mathrm{L} \mathrm{NaCl} / 14.2 \mathrm{~g} / \mathrm{L} \mathrm{Na} \mathrm{SO}_{4}$ and $8.4 \mathrm{~g} / \mathrm{L}$ $\mathrm{NaHCO}_{3}$. The solution was ultimately autoclaved at $121^{\circ} \mathrm{C}$ and stored at $4{ }^{\circ} \mathrm{C}$, for further use.

The bacterial medium was prepared through the SRB stains, in the form of Desulfovibrio desulfaricans. Firstly, the stains were isolated from the soil which was tested. Secondly, the stains were anaerobically incubated in an API RP-38 g/L medium, containing $0.2 \mathrm{MgSO}_{4}, 7 \mathrm{H}_{2} \mathrm{O}, 1.0$ ascorbic acid, $10.0 \mathrm{NaCl}, 0.5 \mathrm{KH}_{2} \mathrm{PO}_{4}$, 4.0 sodium lactate, 1.0 yeast extract and $0.02 \mathrm{Fe}\left(\mathrm{NH}_{4}\right)_{2}\left(\mathrm{SO}_{4}\right)_{2}$. Then, the incubated medium was purified in a sterile inoculation loop. Lastly, $20 \mathrm{~mL}$ of the culture containing SRB were subsequently transferred into $1 \mathrm{~L}$ of sterilized SSS. Ultimately, two days post the incubation, the finely ground electrodes were hung in the medium with the bacteria in a sealed jar of $1 \mathrm{~L}$, for the corrosion measurement.

\section{Preparation of the specimen and crevice cell}

An insulated copper wire was attached onto each sample surface, using an aluminium conducting tape. The samples were cold mounted into nonconductive epoxy resin. The coupons were then ground from 240 to 1000 by grit sand papers. Ultimately, the samples were polished to mirror like shapes and washed with a soap solution, followed by rinsing in distilled water and acetone, to remove residual surface water. The cleaning operation was performed quickly, to avoid premature corrosion. In coated polyurethane, with low carbon steel as base material, it was drilled a hole of $0.7 \mathrm{~cm}^{2}$, as shown in Fig. 1, for the simulation of cathodic disbondment, which occurs on coated steels. The hole was created to simulate the initial point of failure on polymeric-coated low carbon SPs. So, by applying various $\mathrm{CP}$ potentials at the point of failure, the impact of differently applied CPs was monitored. The main aim was to get the one which would not cause CD.

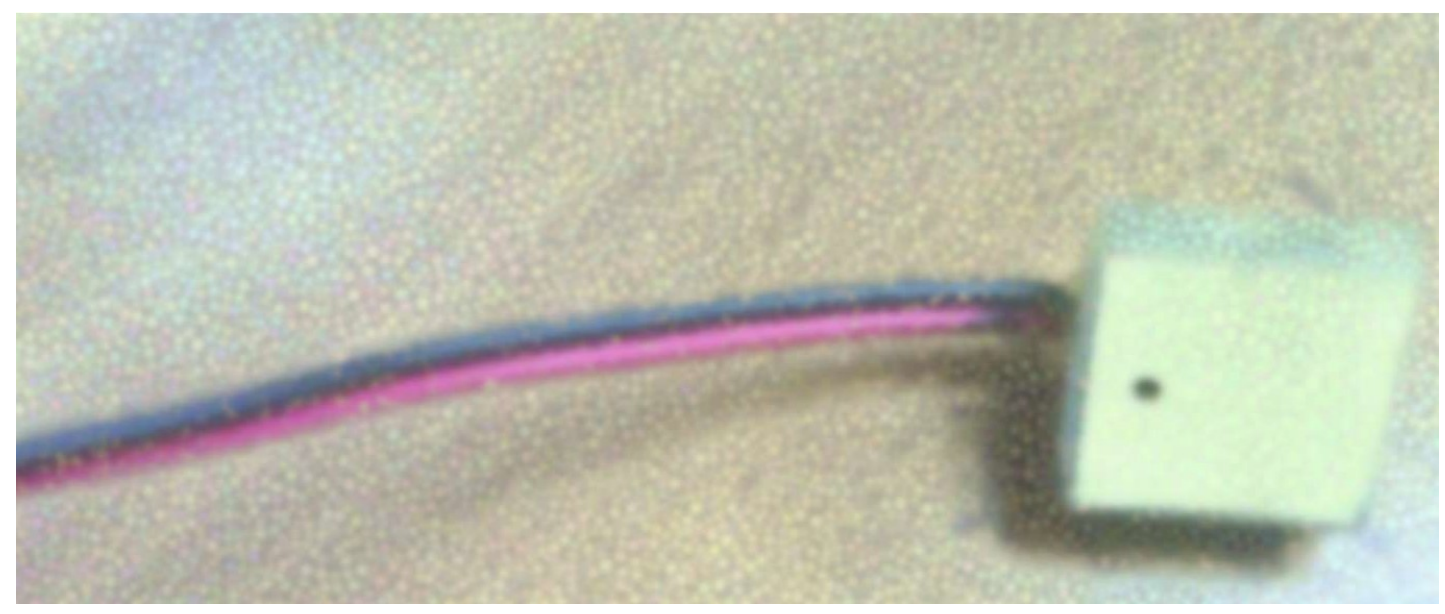

Figure 1. Coated steel electrode with a defect embedded in epoxy resin. 


\section{Electrochemical measurements and SRB cell counts}

Electrochemical measurements (OCP, PDP and EIS) were conducted using an appropriate three-electrode standard cell with: a working electrode (steel); a counter electrode (graphite); and a reference electrode $(\mathrm{Ag} / \mathrm{AgCl})$. However, as corrosion standards are in reference to $\mathrm{Cu} / \mathrm{CuSO}_{4}$, the measurements have been converted to it. An electrode, which was characterized in a bacterial medium, was polarized at $-1300 \mathrm{mV}$, to remove oxide formed on its surface in air, while other electrode was polarized at $-250 \mathrm{mV}$. OCP was then run at room temperature, in both sterilized and bacterial media, until steady-state conditions were reached. After OCP, PDP and EIS measurements were carried out and triplicated for each sample. The reported average potentials were plotted versus the $\mathrm{Ag} / \mathrm{AgCl}$ reference electrode. For quantification, the three tube multiple most probable number (MPN), with a three parallel method, was utilized.

Slow strain rate tensile test (SSRT)

The SCC susceptibility of the defected coating, under SRB presence, was investigated using SSRT. The prepared sample shown in Fig. 1 was taken to SSRT controlled at $1 \times 10^{-6} \mathrm{~S}^{-1}$. The SCC susceptibility was expressed in terms of percentage change in the reduction in area (RA). The lower was the RA, the higher was the SCC susceptibility. RA was calculated by Eq. 1 below:

$$
\mathrm{RA}=\frac{S o-S A}{s o} \times 100 \%
$$

where $S_{O}$ is the initial area of the tensile specimen and $S_{A}$ is the final fracture area of the tensile specimen.

\section{Surface analysis}

High resolution scanning electron microscope (SEM), equipped with a field emission cathode and coupled to an energy dispersive x-ray (EDX), was used to characterize soils. SEM was used to characterize the surface morphologies, while EDX was used for quantitative elemental analyses through INCA software. Prior to characterization, all the samples were carbon coated, in order to make surfaces conductive.

\section{Results and discussion}

Potentiodynamic polarization (PDP)

Fig. 2 shows PDP curves obtained from electrochemical measurements in a bacterial medium (with SRB) and in a sterilised medium (without SRB). From the curves, it can be seen that they do not show any passivation on their anodic sites (reactions). That shows that PS dissolution occurred in both media. Low carbon steel generally exhibits active corrosion behaviour (does not form a strong passivation layer) [19], and this is due to the dissolution matrix of constituent elements, which do not facilitate the formation of any intrinsic passivation layer [20]. 
There is a notable difference on corrosion potential between media. In fact, as it can be seen in Fig. 2, the corrosion potential of the medium without SRB is more negative than that of the medium with SRB. Cathodic and anodic curves show a higher current density in the medium with SRB than that in the sterilized SSS (medium without SRB). As the corrosion rate is more important than the corrosion potential, subsequent measurements were extensively focused on bacterial media.

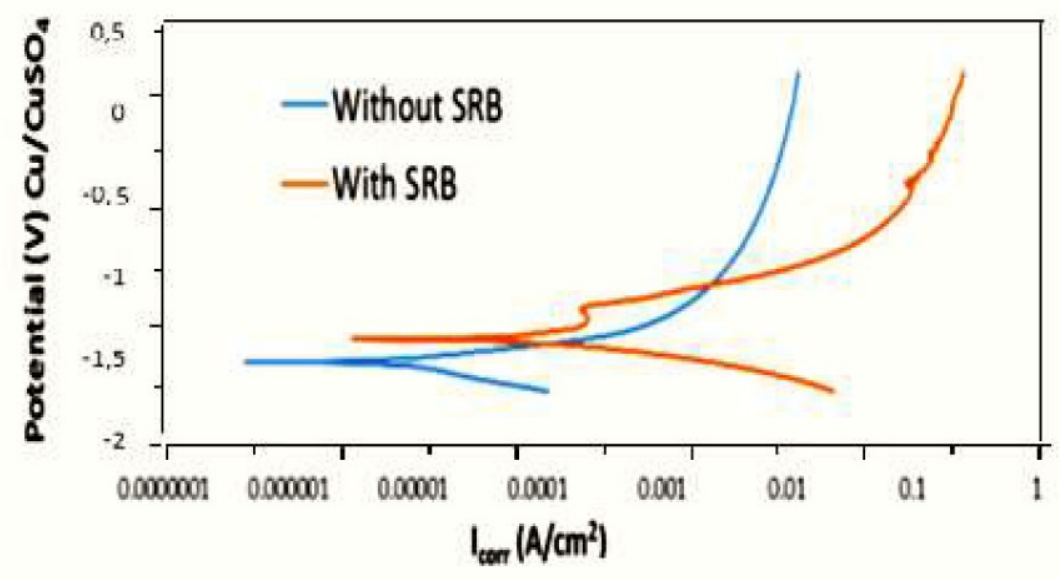

Figure 2. PDP curves under sterilized and bacterial media.

\section{Variation of SRB numbers}

From Fig. 3, it can be seen that the SRB growth process in the bacterial medium is categorized into three stages. Clearly, the SRB number increased exponentially from day 1 to day 9, and remained almost stationary between day 9 and $11^{\text {th }}$ day. The SRB growth dropped after the $12^{\text {th }}$ day. On stage 1 , the number of SRB increased rapidly and reached the maximum level on the $9^{\text {th }}$ day; on stage 2 , the growth ceased, as bacteria started to die; and the stage 3 is called death phase, as evidenced by the decline in the curve on Fig. 3.

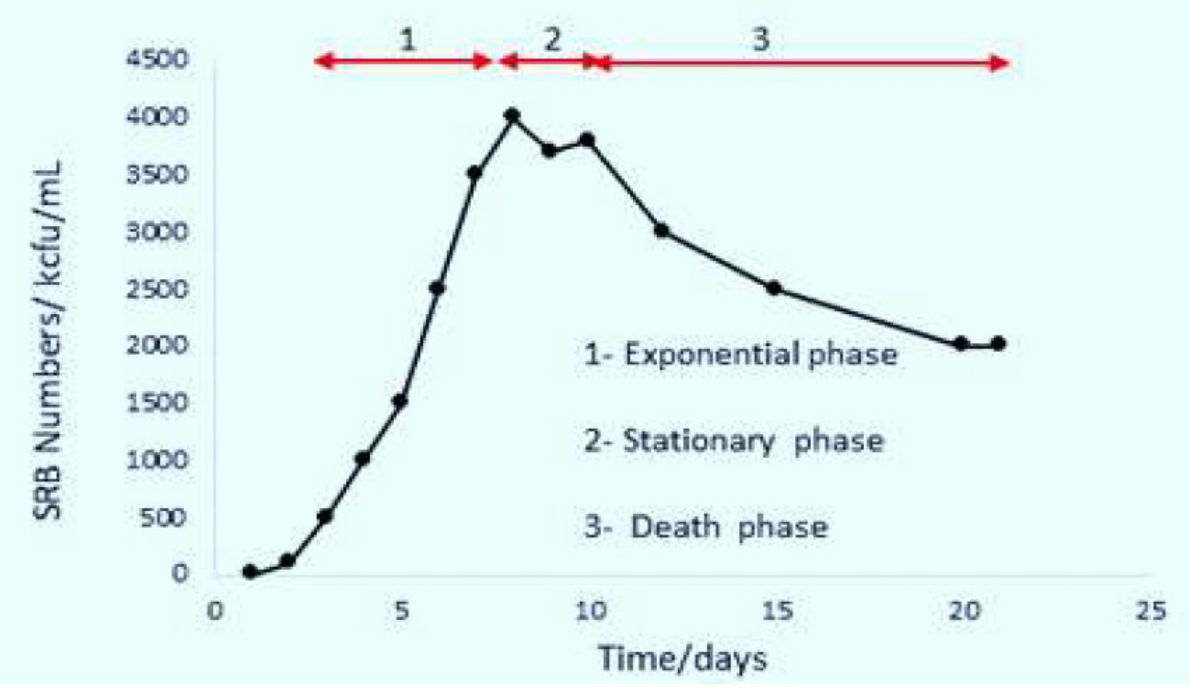

Figure 3. SRB variation, as a function of time, in an incubated medium. 


\section{Electrochemical Impedance Spectroscopy (EIS)}

EIS is, so far, deemed as the chief electrochemical technique in further characterization of kinetics parameters of electrochemical reactions taking place in any corrosion process [21]. The tests in Fig. 3 were carried out at OCP, to study the effect of microbiological activities, as a function of time, on bacterial media. The first semi-circular in Fig. 3 was more compressed than other semicircles. Contrarily, the semi-circular on the $9^{\text {th }}$ day was the widest at the high frequency region. Thereafter, as evidenced by compressed semicircles, the corrosion reactions became rapid after the 12 th day, and became even worse on the $20^{\text {th }}$ day. That indicates an occurrence of rapid corrosion reactions on the electrode surface, on the $1^{\text {st }}$ day, which declined as days went by, up to the $9^{\text {th }}$ day. After the $9^{\text {th }}$ day, as based on compressed semicircles, the rapid reactions commenced. As observed in Fig. 3, there are three phases formed during SRB growth. This shows that biofilms are effective during their exponential growth and stationary phases. These are also evidenced by semi circles in Fig. 4. Furthermore, observations also attest to the previous findings [11], and these show that SRB could be providing protection to SP; but only momentarily and fraught with uncertainties, as time goes on.

In Fig. $5, \mathrm{CP}$ potentials were applied after the $20^{\text {th }}$ day, and the comparison was done with OCP, under the Nyquist diagrams. As it can be seen, the semicircles diameter became wider from the first potential to the last potential. The noted applied potential was up to $-1890 \mathrm{mV} \mathrm{Cu} / \mathrm{CuSO}_{4}$. Here, it can be seen that anaerobic conditions necessitate a more negative potential for corrosion mitigation on PS. Nonetheless, a more depressed semi-circular was found at $-950 \mathrm{mv}$ and $1890 \mathrm{mV} \mathrm{Cu} / \mathrm{CuSO}_{4}$, as it can be seen in Fig. 5a. These semicircles are associated with rapid corrosion processes at the steel/solution interface, due to a higher hydrogen generation in the solution, and to a negative diffusion into the steel electrode. Phase angles of about $3.7^{\circ}$ and $8^{\mathrm{O}}$ were also observed in Fig. 5b, and that, as well, shows rapid corrosion occurrence on the steel surface. Significantly, a high-frequency loop was observed when the applied potential was $-1450 \mathrm{mV}$ $\mathrm{Cu} / \mathrm{CuSO}_{4}$. This potential had a better phase angle of about $25^{\circ}$ in the lowfrequency region, as it can be seen in Fig. 5b. These observations are also corroborated by higher impedance values at an intermitted frequency, when a CP potential of $1450 \mathrm{mV} \mathrm{Cu} / \mathrm{CuSO}_{4}$ was applied on the steel electrode, as it can be seen in Fig. 5c. This shows typical characteristics of a Warburg impedance, and an occurrence of the diffusion process on the steel electrode surface [22, 23]. 


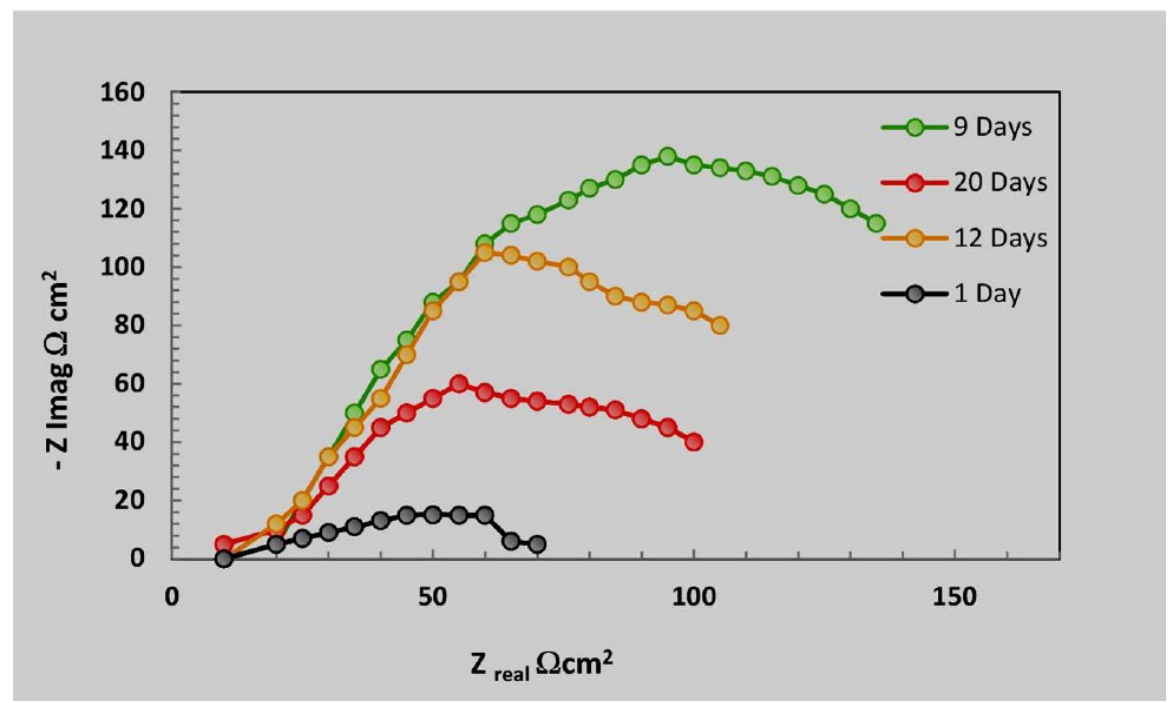

Figure 4. Nyquist diagrams of an incubated (bacterial) medium, as a function of time.
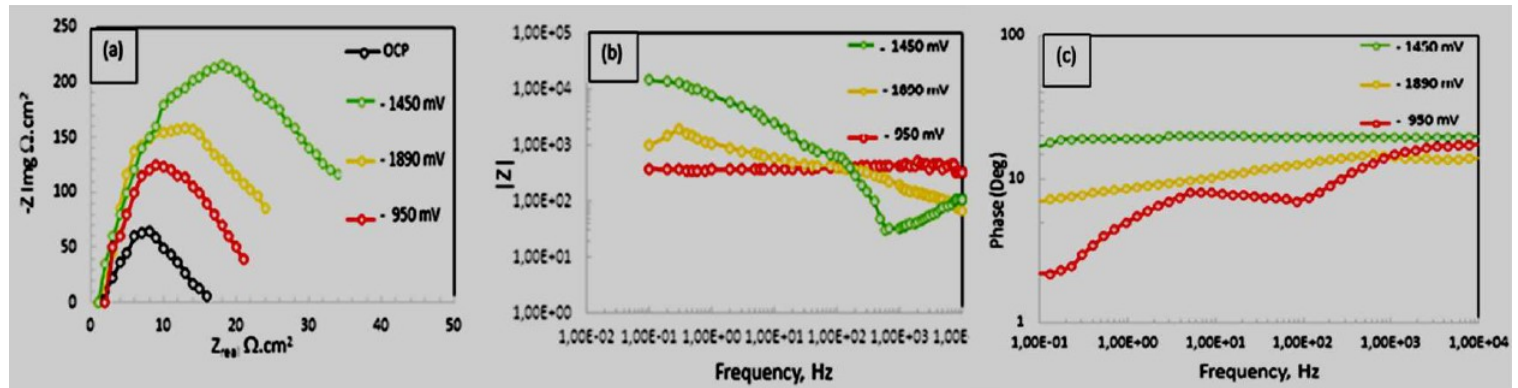

Figure 5. EIS curves of low carbon steel electrodes under differently applied CP potentials in a SRB solution: (a) nyquist diagrams; (b) bode plots; (c) phase plots.

Table 1 shows EIS spectra at OCP and under different CP potentials.

Table 1. EIS spectra at OCP and under different CP potentials.

\begin{tabular}{|c|c|c|c|c|c|c|}
\hline $\begin{array}{c}\text { Potential } \\
(\mathrm{mV})\end{array}$ & $\begin{array}{c}R_{\mathrm{s}} \\
\left(\Omega \mathbf{c m}^{2}\right)\end{array}$ & $\begin{array}{c}\mathrm{C}_{\mathrm{dl}} \\
\left(\mathbf{F ~ \mathrm { cm } ^ { - 2 }}\right)\end{array}$ & $\begin{array}{c}R_{\mathrm{ct}} \\
\left(\Omega \mathrm{cm}^{2}\right)\end{array}$ & $\begin{array}{c}\mathbf{Q}-\mathbf{Y}_{\mathbf{o}} \\
\left(\mathbf{S}^{\mathrm{n} / \Omega} / \Omega\right)\end{array}$ & Q-n & $\begin{array}{c}\mathbf{R}_{\mathbf{f}} \\
(\Omega \\
\left.\mathbf{c m}^{2}\right)\end{array}$ \\
\hline $\begin{array}{l}\text { OCP } \\
(-720 \mathrm{mV})\end{array}$ & 16.389 & 0.000796 & 1491 & 0.000921 & 0.7213 & 334.6 \\
\hline$-950 \mathrm{mV}$ & 12.321 & 0.000893 & 1556 & 0.000528 & 0.5431 & 250.4 \\
\hline$-1450 \mathrm{mV}$ & 8.965 & 0.000321 & 3246 & 0.000213 & 0.5693 & 349.1 \\
\hline$-1890 \mathrm{mV}$ & 14.993 & 0.000985 & 2236 & 0.000184 & 0.2189 & 85.2 \\
\hline
\end{tabular}

Fig. 6 shows an equivalent circuit for steel specimens in a simulated soil solution, at different applied potentials 


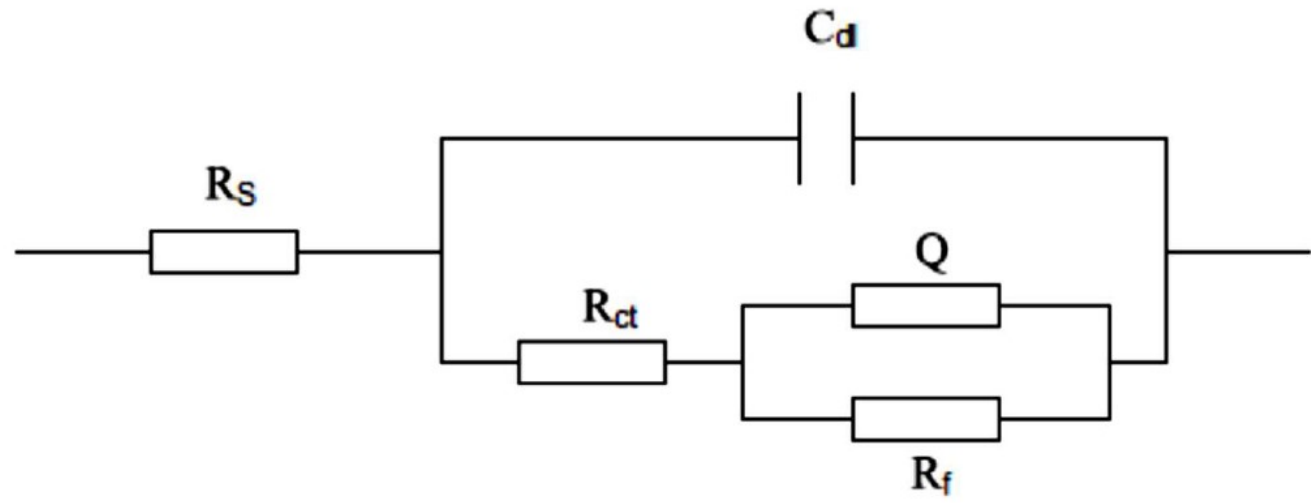

Figure 6. Equivalent circuit for steel specimens in a simulated soil solution, at different applied potentials.

SSRT of low carbon steel at different potentials in a soil simulation solution Fig. 7 below shows analysis of steel electrodes from SSRT exposed to the air, OCP and under three different CP Potentials. It can be seen that the electrode tested in air had the highest strain percentage (\%), which was around $13.8 \%$, as it can be seen in Fig. 7, while the lowest strain was observed at $-1100 \mathrm{mV}$. Notably, stress at OCP and three CP potentials increased variably. These differences were accentuated by the RA. The calculated RA percentage was the highest at air $(63 \%)$, and it was the lowest at $-1890 \mathrm{mV}(36 \%)$. At $-720 \mathrm{mV}, \quad-950 \mathrm{mV}$ and $1450 \mathrm{mV} \mathrm{OCPs}$, for $\mathrm{Cu} / \mathrm{CuSO}_{4}$, the RA was $45 \%, 51 \%$ and $56 \%$, respectively. So, comparatively, based on RA \%, it is clear that a highly negative CP potential ($1890 \mathrm{mV}$ ) has worsened the susceptibility of SCC on SPs.

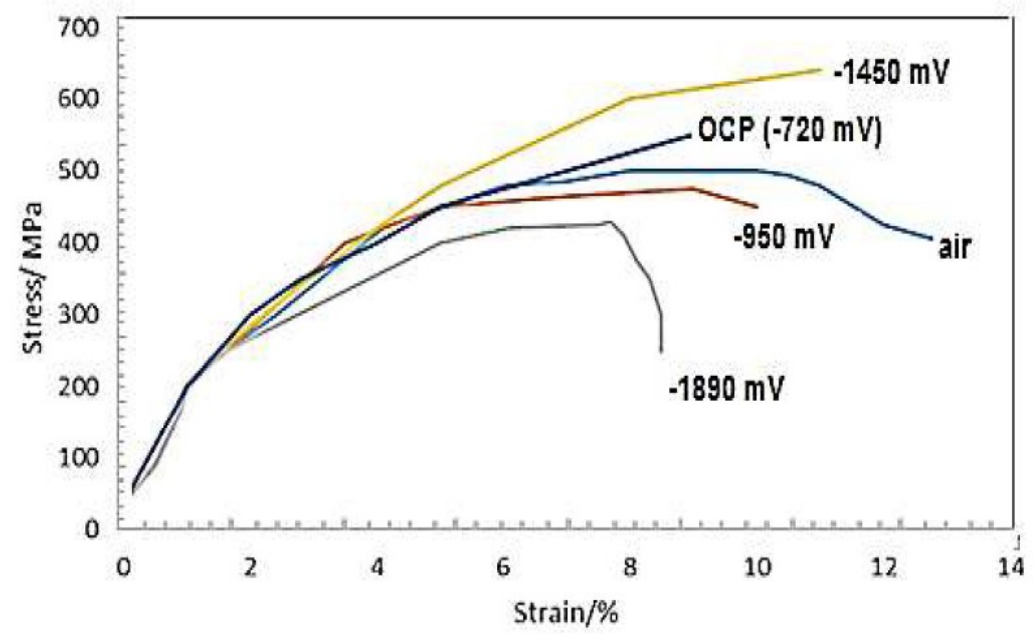

Figure 7. Stress-strain curves of steel with differently applied potentials in a SRB solution.

\section{Surface morphology}

Fig. 8 shows SEM/EDX analysis on electrodes buried in a bacterial medium under different conditions. 


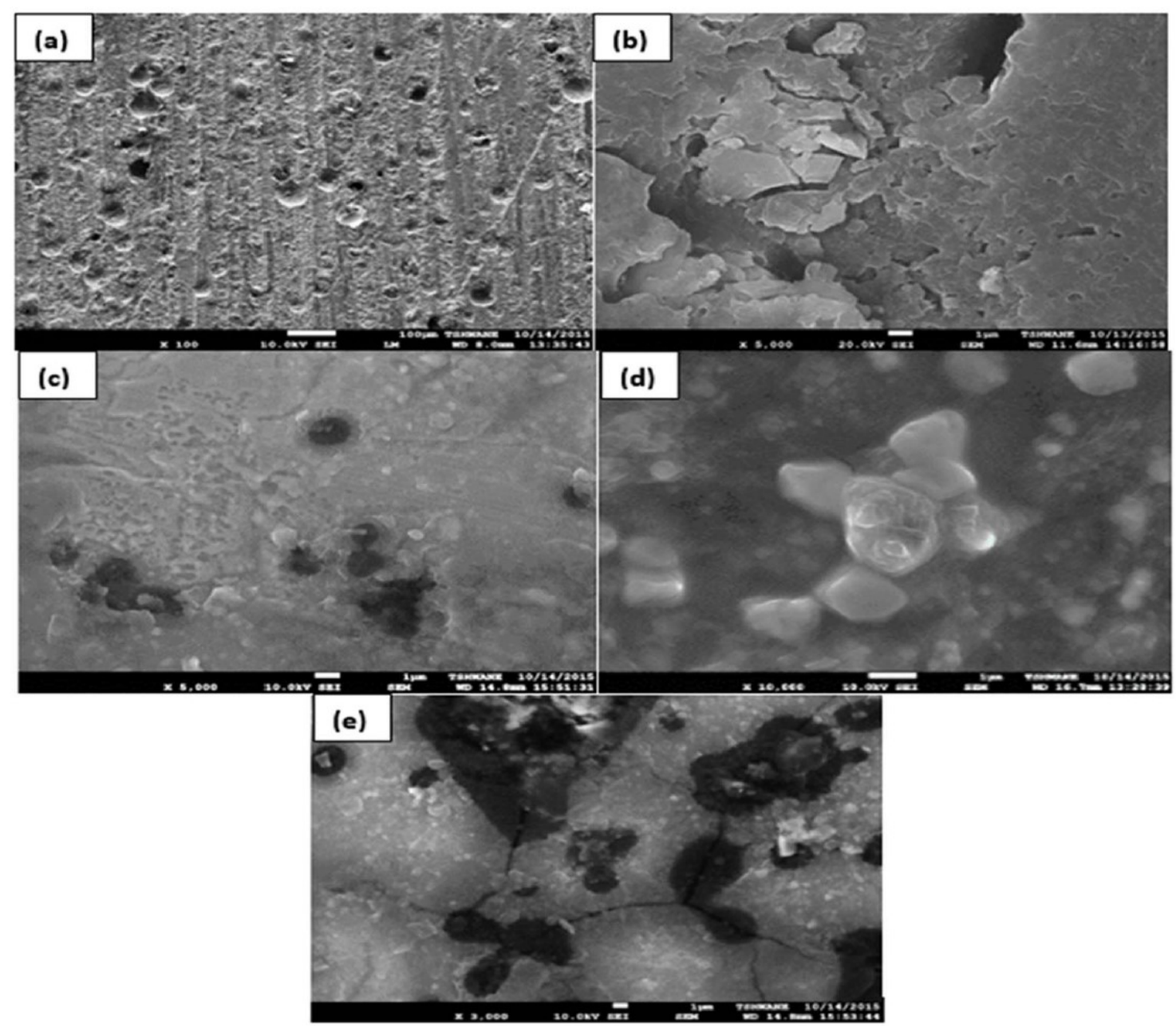

Figure 8. Surface fracture morphology of steel with different applied potentials after SSRT in a simulated soil solution: (a) in air; (b) at $-720 \mathrm{mV}$; (c) $-950 \mathrm{mV}$; (d) $-1450 \mathrm{mV}$ and (e) $-1890 \mathrm{mV}$ OCPs.

From Fig. 8 (a), cracks can straightforwardly be observed on the electrode surface. The EDX analysis also shows the highest amount of sulfur (S) content. The oxides on the surface were made of iron oxide and mackinawite. In later cases, as explained earlier, sulfate was converted to sulphides [24]. Ultimately, hydrogen sulfide occurred and, consequently, the corrosion on LCSP accelerated, as demonstrated in Figs. 8 (b) and (c).

Under synergistic protection offered by coating and $\mathrm{CP}$, an oxide lifting was observed, as denoted in Fig. 8 (d). This could be due to soil conditions which are dangerously affected by a negative CP $(-1450 \mathrm{mV})$. Cautiously, black corrosion products with oxide lifting were examined. On the other hand, an iron carbide phase was detected around artificial defects of electrodes exposed to a higher negative potential, as it can be noticed in Fig. 8 (e). 


\section{Conclusions}

In this study, measurements were carried out under sterilized and bacterial media. An incubation of SRB microorganisms was carried out for the detection, quantification and effects of SRB on SPs, during their microbial activities.

From the analysis, the incubated medium showed a high level of microorganisms, which is regarded to be toxic on PSs. Three phases were also noted during the growth of SRB in the bacterial medium, and EIS measurements showed that effects of biofilms on SPs varied with time. Corrosion processes were mild during exponential and death phases, and rapid during declining phase. From the potentiodynamic polarization results, the corrosion potential of the medium without SRB (sterile) was more negative than that of the one in the bacterial medium, while the cathodic curves showed a higher current density (corrosion rate) in the medium with SRB than in that of the sterilized medium.

On effectiveness of CP in SRB presence, EIS results confirmed SSRT and SEM results as the most compressed semi-circular at a low frequency of $-1890 \mathrm{mV}$ for $\mathrm{Cu} / \mathrm{CuSO}_{4}$, but a wide diameter semi-circular was discovered at $-1450 \mathrm{mV}$ for $\mathrm{Cu} / \mathrm{CuSO}_{4}$.

Surface morphologies of electrodes buried in the bacterial medium also revealed dimples on the entire electrode surface, when SSRT was carried in air. A slightly different observation was maintained at OCP. However, when the applied CP potential was $-950 \mathrm{mV}$ for $\mathrm{Cu} / \mathrm{CuSO}_{4}$, quasi-cleavage was discovered on the electrode. At $-1450 \mathrm{mV}$ for $\mathrm{Cu} / \mathrm{CuSO}_{4}$, corrosion products were seen all over the electrode, while a complete cleavage occurred on the electrode at $-1890 \mathrm{mV}$ for $\mathrm{Cu} / \mathrm{CuSO}_{4}$.

\section{Acknowledgement}

We would like to thank Tshwane University of Technology on the fund the study.

\section{References}

1. AlAbbas FM, Williamson C, Bhola SM, et al. Influence of sulfate reducing bacterial biofilm on corrosion behavior of low-alloy, high-strength steel (API5L X80). Int Biodeter Biodegrad. 2013;78:34-42.

2. $\mathrm{Xu} \mathrm{D}, \mathrm{Gu} \mathrm{T}$. Carbon source starvation triggered more aggressive corrosion against carbon steel by the Desulfovibrio vulgaris biofilm. Int Biodeter Biodegrad. 2014;91:74-81.

3. Starosvetsky J, Starosvetsky D, Armon R. Identification of microbiologically influenced corrosion (MIC) in industrial equipment failures. Eng Failure Analy. 2007;14:1500-11.

4. Popov BN, Kumaraguru SP. Cathodic protection of pipelines. Handbook of environmental degradation of materials. Amsterdam: Elsevier; 2005.

5. Abdullah A, Yahaya N, Md Noor N, et al. Microbial corrosion of API 5L X-70 steel by ATCC 7757 and consortium of sulfate-reducing bacteria. J Chem Carbon. 2014 Jan 1;2014. 
6. Kuang F, Wang J, Yan L, et al. Effects of sulfate-reducing bacteria on the corrosion behavior of carbon steel. Electrochim Acta. 2007;52:6084-8.

7. Kakooei S, Ismail MC, Ariwahjoedi B. Mechanisms of microbiologically influenced corrosion: a review. World Appl Sci J. 2012;17:524.

8. Xu LC, Chan KY, Fang HH. Application of atomic force microscopy in the study of microbiologically influenced corrosion. Mat Charact. 2002;48:195203.

9. Usher KM, Kaksonen AH, Cole I, et al. Critical review: microbially influenced corrosion of buried carbon steel pipes. Int Biodeter Biodegrad. 2014;93:84-106.

10. $\mathrm{Xu} \mathrm{J}$, Wang $\mathrm{K}$, Sun $\mathrm{C}$, et al. The effects of sulfate reducing bacteria on corrosion of carbon steel Q235 under simulated disbonded coating by using electrochemical impedance spectroscopy. Corros Sci. 2011;53:1554-62.

11. Chen X, Wang G, Gao F, et al. Effects of sulphate-reducing bacteria on crevice corrosion in X70 pipeline steel under disbonded coatings. Corros Sci. 2015;101:1-1.

12. Usher KM, Kaksonen AH, Bouquet D, et al. The role of bacterial communities and carbon dioxide on the corrosion of steel. Corros Sci. 2015;98:354-65.

13. Wu T, Yan M, Zeng D, et al. Stress corrosion cracking of X80 steel in the presence of sulfate-reducing bacteria. J Mater Sci Technol. 2015;31:413-22.

14. Chen X, Wang G, Gao F, et al. Effects of sulphate-reducing bacteria on crevice corrosion in X70 pipeline steel under disbonded coatings. Corros Sci. 2015;101:1-1.

15. Liu H, Cheng YF. Mechanistic aspects of microbially influenced corrosion of X52 pipeline steel in a thin layer of soil solution containing sulphate-reducing bacteria under various gassing conditions. Corros Sci. 2018;133:178-89.

16. Liu H, Cheng YF. Mechanism of microbiologically influenced corrosion of X52 pipeline steel in a wet soil containing sulfate-reduced bacteria. Electrochim Acta. 2017;253:368-78.

17. Javed MA, Neil WC, McAdam G, et al. Effect of sulphate-reducing bacteria on the microbiologically influenced corrosion of ten different metals using constant test conditions. Int Biodeter Biodegrad. 2017;125:73-85.

18. Wan H, Song D, Zhang D, et al. Corrosion effect of Bacillus cereus on X80 pipeline steel in a Beijing soil environment. Bioelectrochem. 2018;121:18-26.

19. Sekunowo OI, Adeosun SO, Lawal GI. Potentiostatic polarisation responses of mild steel in seawater and acid environments. international J Sci Technol Research. 2013;2:139-45.

20. Wu YH, Liu TM, Luo SX, et al. Corrosion characteristics of Q235 steel in simulated Yingtan soil solutions. Mater Werkst. 2010;41:142-6.

21. Yan M Díaz-Cruz M, Sun C, Xu J, et al. Role of Fe oxides in corrosion of pipeline steel in a red clay soil. Corros Sci. 2014;80:309-17.

22. Laboulais JN, Mata AA, Borrás VA, et al. Electrochemical characterization and passivation behaviour of new beta-titanium alloys (Ti35Nb10Ta-xFe). Electrochim Acta. 2017;227:410-8. 
23. Narozny M, Zakowski K, Darowicki K. Time evolution of Electrochemical Impedance spectra of cathodically protected steel in artificial seawater. Constr Building Mater. 2017;154:88-94.

24. Cervantes-Tobón A, Godínez-Salcedo JG, Gonzalez-Velazquez JL, et al. Corrosion rates of API 5L X-52 and X-65 steels in synthetic brines and brines with $\mathrm{H} 2 \mathrm{~S}$ as a function of rate in a rotating cylinder electrode. Int $\mathbf{J}$ Electrochem Sci. 2014;9:2454-69. 